\title{
Occurrence of microplastics in edible aquatic insect Pantala sp. (Odonata: Libellulidae) from rice fields
}

\author{
Witwisitpong Maneechan $^{1}$, Taeng On Prommi ${ }^{\text {Corresp. } 2}$ \\ ${ }^{1}$ Program of Bioproducts Science, Department of Science, Faculty of Liberal Arts and Science, Kasetsart University, Kamphaeng Saen Campus, Nakhon \\ Pathom, Thailand \\ 2 Department of Science, Faculty of Liberal Arts and Science, Kasetsart University, Kamphaeng Saen Campus, Nakhon Pathom, Thailand \\ Corresponding Author: Taeng On Prommi \\ Email address: faastop@ku.ac.th
}

Background. Microplastic (MP) contamination has been discovered in aquatic systems throughout the world. They are well-known as contaminants in aquatic species, but there is a gap in understanding about pathways of MP contamination into humans (i.e., through aquatic animals). The goal of this study is to assess MP contamination in an edible aquatic insect (Pantala sp.) living in rice fields.

Methods. A dragonfly larva, Pantala sp. (Odonata: Libellulidae), was tested for MPs. The study concentrated on three distinct anatomical compartments (whole body, gastrointestinal tract, and body without gastrointestinal tract), each of which was examined separately. For the physical identification and chemical analysis of MPs, a stereomicroscope and a Fourier Transformed Infrared Spectroscope (FTIR) were used, respectively.

Results and Discussion. The microplastics content was 121 in the whole body, 95 in the gastrointestinal tract, and 66 in the body without the gastrointestinal tract, with an average of $1.34 \pm$ $1.11,1.06 \pm 0.77$, and $0.73 \pm 0.51$ abundance/ individual, respectively. The most common MPs discovered during this study were fragments, followed by fibers and rods. The chemical analysis by FT-IR confirmed three different polymers, including polymethyl methacrylate (PMMA), polyethylene terephthalate (PET), and polypropylene (PP). There was no significant difference in MP abundances among the sample types (Kruskal-Wallis chi-squared $=2.774, \mathrm{df}=2, p=0.250$ ). The findings suggest that eating an edible aquatic insect (Odonata: Pantala sp.) could be one way for humans to MPs. This is concerning as the potential risks of MPs can cause neurotoxicity and an increased cancer risk in humans. 
1 Occurrence of microplastics in edible aquatic insect Pantala sp. (Odonata: Libellulidae)

2 from rice field

3 Witwisitpong Maneechan ${ }^{1}$, Taeng On Prommi²

$4{ }^{1}$ Program of Bioproducts Science, Department of Science, Faculty of Liberal Arts and Science,

5 Kasetsart University, Kamphaeng Saen Campus, Nakhon Pathom, 73140, Thailand

$6 \quad 2$ Department of Science, Faculty of Liberal Arts and Science, Kasetsart University, Kamphaeng

7 Saen Campus, Nakhon Pathom, 73140, Thailand

8 Corresponding Author:

$9 \quad$ Taeng On Prommi ${ }^{1}$

10 Department of Science, Faculty of Liberal Arts and Science, Kasetsart University, Kamphaeng

11 Saen Campus, Nakhon Pathom, 73140, Thailand

12 Email address: faastop@ku.ac.th 


\section{Occurrence of microplastics in edible aquatic insect Pantala sp. (Odonata: Libellulidae)} from rice field

\section{Witwisitpong Maneechan ${ }^{1}$, Taeng On Prommi ${ }^{2}$}

${ }^{1}$ Program of Bioproducts Science, Department of Science, Faculty of Liberal Arts and Science, Kasetsart University, Kamphaeng Saen Campus, Nakhon Pathom, 73140, Thailand

${ }^{2}$ Department of Science, Faculty of Liberal Arts and Science, Kasetsart University, Kamphaeng Saen Campus, Nakhon Pathom, 73140, Thailand

Corresponding Author: Taeng On Prommi ${ }^{1}$

Department of Science, Faculty of Liberal Arts and Science, Kasetsart University, Kamphaeng Saen Campus, Nakhon Pathom, 73140, Thailand

Email address: faastop@ku.ac.th

\section{Abstract}

Background. Microplastic (MP) contamination has been discovered in aquatic systems throughout the world. They are well-known as contaminants in aquatic species, but there is a gap in understanding about pathways of MP contamination into humans (i.e., through aquatic animals). The goal of this study is to assess MP contamination in an edible aquatic insect (Pantala sp.) living in rice fields.

Methods. A dragonfly larva, Pantala sp. (Odonata: Libellulidae), was tested for MPs. The study concentrated on three distinct anatomical compartments (whole body, gastrointestinal tract, and body without gastrointestinal tract), each of which was examined separately. For the physical identification and chemical analysis of MPs, a stereomicroscope and a Fourier Transformed Infrared Spectroscope (FT-IR) were used, respectively.

Results and Discussion. The microplastics content was 121 in the whole body, 95 in the gastrointestinal tract, and 66 in the body without the gastrointestinal tract, with an average of $1.34 \pm 1.11,1.06 \pm 0.77$, and $0.73 \pm 0.51$ abundance/ individual, respectively. The most common MPs discovered during this study were fragments, followed by fibers and rods. The chemical analysis by FT-IR confirmed three different polymers, including polymethyl methacrylate (PMMA), polyethylene terephthalate (PET), and polypropylene (PP). There was no significant difference in MP abundances among the sample types (Kruskal-Wallis chi-squared $=2.774$, $\mathrm{df}=$ $2, p=0.250$ ). The findings suggest that eating an edible aquatic insect (Odonata: Pantala sp.) could be one way for humans to consume MPs. This is concerning as the potential risks of MPs can cause neurotoxicity and an increased cancer risk in humans.

\section{Introduction}


Plastic usage and misuse has been noted as a major environmental issue in both aquatic and terrestrial environments (Wright, Thompson \& Galloway, 2013; Bläsing \& Amelung, 2018). The continuous increase in the discharge of plastics into the environment, as a result of the growing human population, is one of the main sources of plastic pollution (Thompson et al., 2004; Nel et al., 2017). Microplastics (MPs) are plastic particles with a diameter of less than $5 \mathrm{~mm}$ (GESAMP, 2015). These MPs are generally categorized as primary MPs (manufactured for addition to certain products) or secondary MPs (derived from the breakdown of larger plastics) based on their structure and chemical composition (Cole et al., 2011; Ehlers, Manz \& Koop, 2019; Arthur, Baker \& Bamford, 2009). Microplastic pollution has been reported in a variety of environments and species across the world. Although numerous research has been conducted to explore the occurrence, abundance, and dispersion of MPs in the marine environment, only a few have focused on microplastics in freshwater habitats (Free et al., 2014; Horton et al., 2017; Mani, Hauk, Walter \& Burkhardt-Holm, 2015; Castañeda, Avlijas, Simard \& Ricciardi, 2014; Dris et al., 2015). Microplastic debris contaminates freshwater habitats such as streams, rivers, and lakes (Eerkes-Medrano, Thompson \& Aldridge, 2015). Plastic contamination can have an impact on the organisms being exposed. Microplastics can be consumed by a wide range of animals from zooplankton to large vertebrates, and they are primarily accumulated in the stomach (Qiao et al., 2019). Therefore, these concerns of MP contamination are growing rapidly since ingestion is more likely in lower trophic organisms, which transfers via the food chain (Al-Jaibachi, 2019).

Rice field ecosystems function as temporary wetlands, which are a unique man-made environment that connects and shares water with natural wetlands (Al-Shami et al., 2010; Lutz, Kehr \& Fernández, 2015; Wakhid et al., 2020). According to Heckman (1974), who recorded a total of 589 species of organisms on a rice field over the period of a year, including edible aquatic insects, rice fields contain a remarkable high biodiversity. Insects with aquatic larvae have been documented as human food in 48 countries throughout the world. Macadam \& Stockan (2017) reported that the Coleoptera have the most edible food insects (79 species) utilized, followed by Odonata ( 58 species) and Hemiptera ( 55 species).

An overview of the nutritional makeup of Odonata insects was shown in a previous study (Feng et al., 2001; Xiaoming et al., 2010; Narzari, Sarmah \& Gupta, 2017). The nymphal stage of aquatic insects such as dragonflies (Order Odonata) can be consumed because it is easier to capture than the adult form. The larvae contain all of the nutrients, including protein, lipids, amino acids, and microelements. Dragonfly nymphs (Libellulidae, Aeshnidae, Gomphidae) are commonly consumed in China (Ying et al., 2001; Macadam \& Stockan, 2017; Williams \& Williams, 2017), India (Chakravorty, Ghosh \& Meyer-Rochow, 2013), the Philippines (DeFoliart, 1992), Laos (Pemberton, 1995; Hanboonsong \& Durst, 2014; Barennes, Phimmasane \& Rajaonarivo, 2015), and Thailand (Hanboonsong, 2010).

It is well known that edible aquatic insects with high nutritional content are consumed in Thailand. The preference for Libellulidae (Pantala sp.) species in the Northern and Northeastern parts of this country is remarkable. These nymphs are pale greenish with light brown markings (Bright, 2010). They are aggressive, fast-growing predators that adapt well to lentic habitats, including man-made habitats. Although this species has a worldwide distribution, it is uncommon in Europe (Kiany \& Minaei, 2010; Günther, 2019). Based on the habitat, a dragonfly larva (Pantala sp.) may ingest MPs for several reasons. They feed on a wide variety of prey, including zooplankton and smaller macroinvertebrates (Byers, 1940; Lamb, 1924; Warren, 
1915). According to the findings on MPs in freshwater sediment reviewed by Yang et al. (2021), dragonfly larvae may confuse MP particles with prey and ingest them. Thus, these MP pollutants can be transferred to Pantala sp. and other predators such as fish, birds, and humans. This is concerning as we would expect there to be double the number of MPs in the whole body as it includes both the gastrointestinal tract and other tissues. The goal of this study is to investigate MP contamination in an edible aquatic dragonfly, Pantala sp. (Odonata: Libellulidae), that is consumed by people in many parts of Thailand.

\section{Materials \& Methods}

\section{Study area}

Samples were taken from a rice field in the Kasetsart University Kamphaeng Saen campus, Kamphaeng Saen district, Nakhon Pathom province, central Thailand (N 14 $00^{\prime} 32.2474$ E 99 $58^{\prime} 54.1744$ ) (Fig. 1).

\section{Collection and identification of samples}

Aquatic insects were sampled at random along the edge of the rice plots in October 2020 using an aquatic dip net (dimensions $30 \times 30 \mathrm{~cm}, 250 \mathrm{~m}$ mesh, $50 \mathrm{~cm}$ length). According to our preliminary samplings, several aquatic insects were discovered towards the margin of the rice plot, due to the greater volume of water. As a result, this section of the rice plot was sampled. For such a rice plot, samples were taken along 3 meters on each side. Aquatic insect collections were made in each plot by dragging a dip net down the ground for 3 meters along the margin of the rice plot. Because aquatic insects have high water content, aquatic insects caught in the net were collected and preserved in vials containing $95 \%$ alcohol. The standard keys were used to identify aquatic insects up to the lowest taxonomic level (Dudgeon, 1999; Yule \& Yong, 2004). The nymph of Pantala sp. (Odonata, Libellulidae) was used in this research as an aquatic insect for MP analysis (Fig. 2). In addition, more Pantala sp. were collected in the same rice field for the MPs' investigation in October 2021.

\section{Preparation of Pantala sp. larvae}

Only the Pantala sp. taxa were used for the microplastic investigation. For the study, a total of 180 Pantala sp. specimens of comparable weight were analyzed. Three times distilled water was used to wash the fresh preserved specimens. To assess MPs from Pantala sp., 5 specimens (x 18 replicates) of the whole body, 5 specimens (x 18 replicates) of the gastrointestinal tract (GT) alone, and 5 specimens (x 18 replicates) of the body without the GT were pooled. The specimens were dissected individually using scissors and forceps. All replicates were transferred to a $25 \mathrm{~mL}$ erlenmeyer flask. The entire body, the GT, and the body without the GT weight were all measured for wet weight. The results were presented as a mean \pm standard deviation.

\section{$\mathrm{H}_{2} \mathrm{O}_{2}$ treatment}

Each pooled sample was placed in one erlenmeyer flask and eighteen replicates were prepared for each sample type. To digest the organic materials, $10 \mathrm{~mL}$ of a hydrogen peroxide solution $\left(30 \% \mathrm{H}_{2} \mathrm{O}_{2}\right)$ was added to each flask (Ehlers, Manz \& Koop, 2019). After that, the flasks were wrapped in parafilm and stored at room temperature for 7 days. 


\section{Floatation and filtration}

Following tissue disintegration, potassium formate (99\%) was employed for density of separation the resulting dissolved liquid from soft tissues (Ehlers, Manz \& Koop, 2019). Each sample was placed in a glass separatory funnel, which was then filled with approximately $16 \mathrm{~g}$ of potassium formate and shaken to separate the solution. Because of its less dense form, saturated potassium formate solution facilitates the separation of the microplastic layer after about 4 hours. The undissolved inorganic residues were then drained, and the supernatant was vacuum filtered onto nylon membrane filters (pore size of $0.45 \mu \mathrm{m}$; diameter of $47 \mathrm{~mm}$ ). The filter was then placed in clean glass petri dishes with aluminum foil covers and dried for two days in a $50^{\circ} \mathrm{C}$ drying cabinet.

\section{Contamination control}

To avoid contamination from airborne MPs, all containers and equipment were cleaned with distilled water and covered with aluminum foil when not in use. Exclusive gloves (nitrile), steel, and glass devices were always used at the laboratory. Before beginning labwork, the scissors and forceps were rinsed three times with deionized water. Lab surfaces were thoroughly cleaned with $70 \%$ ethanol. At every stage of the analysis, blanks were run without tissues in parallel with the same procedure used for the samples. All the experimental procedures were finished as soon as possible.

\section{Microplastic observation and polymer identification}

Under a stereomicroscope (Leica EZ4E) with 35x magnification, the filters were visually examined, and photos were obtained at various magnifications to identify MP particle based on their color and type. The MP particles were recorded. A PerkinElmer Spectrum-Fourier transform infrared spectrometer (FT-IR) in attenuated total reflection (ATR) mode was used to verify selected particles (range size 400-500 $\mu \mathrm{m}$ ). The spectral range was 4000 to $500 \mathrm{~cm}^{-1}$, with a $32 \mathrm{~cm}^{-1}$ spectral resolution and $16 \mathrm{co}-\mathrm{scans}$ for each measurement. The characterization of functional groups and the analysis of polymer types were compared to the Bruker spectrum library. Considering the spectrum analysis, the matching degree of spectra with a quality index $\geq 0.7$ was accepted (Woodall et al., 2014).

\section{Data analysis}

The abundance, types, and colors of MPs were counted. Non-parametric analyses were applied as the abundance of MPs was not a normal distribution among the three sample types. KruskalWallis H test was used to test for differences in the mean abundance of MP between sample types, using the Statistical Package for the Social Sciences (SPSS) version 19. Statistical significance was defined as a $\mathrm{p}$-value of less than $0.05(p<0.05)$.

\section{Results and discussion}

Abundance, type and color of MP in edible aquatic insects 
The mean wet weights of Pantala sp. whole body, gastrointestinal (GT) tract only, and body without the GT were $0.3098 \pm 0.0795,0.0399 \pm 0.0133$ and $0.2445 \pm 0.0707 \mathrm{~g}$, respectively. In the controls, no MP particles were found in the blanks. The total number of particles were 121, 95, and 66 in all eighteen replicates of pooled samples (Figure 3A-C), with mean abundance per individual of $1.34 \pm 1.11,1.06 \pm 0.77$ and $0.73 \pm 0.51$ items in the whole body, gastrointestinal (GT) tract, and body without the GT, respectively. Kruskal-Wallis H test revealed no significant differences in the mean abundance of MP particles among sample types (chi-squared $=2.774$, $\mathrm{df}$ $=2, p=0.250$ ) (Table 1). Different types of MPs identified in three samples were fragment, fiber, and rod (Figure 3D-F). The colors of MPs were shown in five different shades of red, green, blue, violet, and orange (Figure 3G-I).

Fragments and fibers were the most common particle types in edible aquatic insects (Odonata), which was similar to prior observations in Nigerian freshwater insects (Akindele, Ehlers \& Koop, 2020). They were found in different sample types in this study, indicating that edible aquatic insects may be vulnerable to MP pollution. The whole bodies had more microplastic items than the other two samples because that is the structure where food and other ingested materials are deposited. In the case of contamination in the body without GT, microplastics could be retained in the exoskeleton of the insect body. Ingestion of MPs, on the other hand, is likely to have different effects on an organism depending on its size, shape, concentrations, and exposure time (Redondo-Hasselerharm et al., 2018).

\section{Identification of microplastic polymers by FT-IR}

A selected 52 plastic-like particles (about 18\% of total MPs) were identified by a Fourier Transformed Infrared Spectroscope (FT-IR). Some particles were confirmed as polymethyl methacrylate (PMMA), polyethylene terephthalate (PET), and polypropylene (PP) (Table 2). For the 52 selected particles, $46.1 \%$ were identified as microplastics, $15.4 \%$ as non-microplastics, and $38.5 \%$ as unidentified particles. The spectral characteristics of these polymers are shown in Figure $4 \mathrm{~A}-\mathrm{C}$.

The findings suggest evidence of detecting MPs in aquatic insects such as Pantala sp. (Odonata: Libellulidae) that humans eat from rice fields. Previously, there are limited research on plastic contamination in Thailand, particularly on aquatic insects in freshwater environments. Recent research (Windsor et al., 2019) revealed data on the occurrence of MP particles in aquatic macroinvertebrates in a riverine valley in South Wales, UK, with the presence of MPs in almost half of the samples (0.14 MPs/mg tissue). Ehlers, Manz \& Koop (2019) conducted a similar study and discovered that MPs (e.g., polypropylene, polyethylene, and polyvinyl chloride) were present in the biological structure of freshwater organisms. Microplastics can also pass through mosquito life stages (i.e., larva, pupa, and adult) and spread throughout aquatic systems (Rhodes, 2019). Furthermore, ingestion of MP polymers was reported in Chironomus sp. (Diptera) (i.e., styrene ethylene butylene styrene, acrylonitrilebutadiene styrene (ABS), chlorinated polyethylene, polypropylene (PP), and polyester), Siphlonurus sp. (Ephemeroptera) (i.e., polyester and $\mathrm{ABS}$ ) and Lestes viridis (Odonata) (i.e., polyester and PP) from Ogun and Osun Rivers, Nigeria (Akindele, Ehlers \& Koop, 2020). As larger plastic debris breaks into smaller 
plastic bits, Cole et al. (2011) discovered that MPs were more likely to be fragments. Also, fibers, and rods were generated from original MPs. Secondary MPs make extrapolating results from single-species and virgin MP investigations challenging (Rummel et al., 2016). One of three ways that freshwater systems become contaminated by MPs are via effluent discharge, overflow of wastewater sewers during high rain events, and run-off from sludge, which all occur in rice fields (Eriksen et al., 2013). Storms and extreme weather conditions, according to can aggravate the flow of MPs from land to water (Cole et al., 2011).

In terms of trophic transfer and the potential for effects across multiple trophic levels, D'Souza et al. (2020) showed that plastics can be transported from invertebrate consumers to predators in natural freshwater ecosystems, including humans. Plastic is contaminating practically every area of the world and its ecosystems, which is a startling fact. However, ocean pollution and plastic deposition on marine animals and sea birds have received the most attention so far. As a result, it is past time for us to focus on freshwater sources as well.

\section{Conclusion}

This is a pilot study that indicates MPs are found in a larval odonate (Pantala sp.), which is consumed by humans in many countries across the world. Certainly, more research into MP pollution in other edible insects are in needed. Finally, there is concern about the potential dangers of MPs, specifically whether and how MP pollution affects human health.

\section{Acknowledgement}

This research project is supported by the National Research Council of Thailand (NRCT): NRCT5-RGJ63002-041.

\section{References}

Akindele EO, Ehlers SM, Koop JH. 2020. Freshwater insects of different feeding guilds ingest microplastics in two Gulf of Guinea tributaries in Nigeria. Environmental Science and Pollution Research 27(26), 33373-33379.

Al-Jaibachi RM. 2019. The ecotoxicological impact of microplastics on freshwater invertebrates. D. Phil. Thesis, University of Reading.

Al-Shami SA, Salmah C, Azizah MS, Abu Hassan A. 2010. The influence of routine agricultural activities on the quality of water in a tropical rice field ecosystem. Applied Ecology and Environmental Research 8(1), 11-18.

APHA. 1992. Standard method for the examination of water and wastewater. $18^{\text {th }}$ ed. American Public Health Association, Washington, D.C. 
243 Arthur C, Baker JE, Bamford HA. 2009. Proceedings of the International Research Workshop on 244 the Occurrence, Effects, and Fate of Microplastic Marine Debris, September 9-11, 2008, 245 University of Washington Tacoma, Tacoma, WA, USA.

246 Barennes H, Phimmasane M, Rajaonarivo C. 2015. Insect consumption to address

247 undernutrition, a national survey on the prevalence of insect consumption among adults and 248 vendors in Laos. PLOS one 10(8), e0136458.

249 Bläsing M, Amelung W. 2018 .Plastics in soil: Analytical methods and possible sources. Science 250 of the total environment $612,422-435$.

251 Bright E. 2010. Aquatic insects of Michigan. Available at http:/www.aquaticinsects.org/ Keys/ 252 Odonata/id_oom_libellulidae_pantala.html (accessed 13 March 2021).

253 Byers CF. 1940. Notes on the emergence and life history of the dragonfly Pantala flavescens. In 254 Proceedings of the Florida Academy of Sciences (Vol. 5, pp. 14-25). Temporary Publisher.

255 Castañeda RA, Avlijas S, Simard MA, Ricciardi A. 2014. Microplastic pollution in St. Lawrence 256 river sediments. Canadian Journal of Fisheries and Aquatic Sciences 71(12), 1767-1771.

258

259

260

261

262

263

264

265

266

267

268

269

270

271

272

273
Chakravorty J, Ghosh S, Meyer-Rochow VB. 2013. Comparative survey of entomophagy and entomotherapeutic practices in six tribes of Eastern Arunachal Pradesh (India). Journal of Ethnobiology and Ethnomedicine 9(1), 1-12.

Cole M, Lindeque P, Halsband C, Galloway TS. 2011. Microplastics as contaminants in the marine environment: a review. Marine pollution bulletin 62(12), 2588-2597.

D’Souza JM, Windsor FM, Santillo D, Ormerod SJ. 2020. Food web transfer of plastics to an apex riverine predator. Global change biology 26(7), 3846-3857.

DeFoliart GR. 1992. Insects as human food: Gene DeFoliart discusses some nutritional and economic aspects. Crop protection 11(5), 395-399.

Dris R, Imhof H, Sanchez W, Gasperi J, Galgani F, Tassin B, Laforsch C. 2015. Beyond the ocean: contamination of freshwater ecosystems with (micro-) plastic particles. Environmental chemistry 12(5), 539-550.

Dudgeon D. 1999. Tropical Asian Stream: Zoobenthos, Ecology and Conservation. Hong Kong University Press, Hong Kong.

Eerkes-Medrano D, Thompson RC, Aldridge DC. 2015. Microplastics in freshwater systems: a review of the emerging threats, identification of knowledge gaps and prioritisation of research needs. Water research 75, 63-82. 
274

275

276

277

278

279

280

281

282

283

284

285

286

287

288

289

290

291

292

293

294

295

296

297

298

299

300

301

302

303

304

305

Ehlers SM, Manz W, Koop JH. 2019. Microplastics of different characteristics are incorporated into the larval cases of the freshwater caddisfly Lepidostoma basale. Aquatic Biology 28, 67-77.

Eriksen M, Mason S, Wilson S, Box C, Zellers A, Edwards W, Amato S. 2013. Microplastic pollution in the surface waters of the Laurentian Great Lakes. Marine pollution bulletin 77(1-2), 177-182.

Feng Y, Chen X, Wang S, Ye S, Chen Y. 2001. Three edible Odonata species and their nutritive value. Forest Research 14(4), 421-424.

Free CM, Jensen OP, Mason SA, Eriksen M, Williamson NJ, Boldgiv B. 2014. High-levels of microplastic pollution in a large, remote, mountain lake. Marine pollution bulletin 85(1), 156163.

GESAMP. 2016. Sources, fate and effects of microplastics in the marine environment: part two of a global assessment. In: Kershaw, P.J. (Ed.) (IMO/FAO/UNESCO-IOC/ UNIDO/ WMO/ IAEA/ UN/ UNEP/ UNDP Joint Group of Experts on the Scientific Aspects of Marine Environmental Protection). Rep. Stud. GESAMP No. 90, 96 pp.

Günther A. 2019. Successful breeding by Pantala flavescens in Germany (Odonata: Libellulidae). Odonatologica 48(3/4), 203-210.

Hanboonsong Y, Durst PB. 2014. Edible insects in Lao PDR: building on tradition to enhance food security. FAO.

Hanboonsong Y. 2010. Edible insects and associated food habits in Thailand. In Forest insects as food: humans bite back, Proceedings of a workshop on Asia-Pacific resources and their potential for developmen. Bangkok, Thailandm: FAO Regional Office for Asia and the Pacific (pp. 173182).

Heckman CW. 1974. The seasonal succession of species in a rice paddy in Vientiane, Laos. Internationale Revue der gesamten Hydrobiologieund Hydrographie 59, 489-507.

Horton AA, Walton A, Spurgeon DJ, Lahive E, Svendsen C. 2017. Microplastics in freshwater and terrestrial environments: evaluating the current understanding to identify the knowledge gaps and future research priorities. Science of the total environment 586, 127-141.

Kiany M, Minaei K. 2010. The Dragonfly Family Libellulidae (Insecta: Odonata: Anisoptera) of Shiraz and its Vicinity (Fars Province, Iran). Iran Agricultural Research 27(1.2), 65-78.

Lamb L. 1924. A tabular account of the differences between the earlier instars of Pantala flavescens (Odonata: Libellulidae). Transactions of the American Entomological Society (1890) 50(4), 289-312. 
Lutz MCG, Kehr AI, Fernández LA. 2015. Abundance, diversity and community characterization of aquatic Coleoptera in a rice field of Northeastern Argentina. Revista de biologia tropical 63(3), 629-638.

Macadam C R, Stockan JA. 2017. The diversity of aquatic insects used as human food. Journal of Insects as Food and Feed 3(3), 203-209.

Mani T, Hauk A, Walter U, Burkhardt-Holm P. 2015. Microplastics profile along the Rhine River. Scientific reports 5(1), 1-7.

Narzari S, Sarmah J, Gupta P. 2017. Nutritional aspects of an aquatic edible insect Sympetrum sp. (Odonata: Libellulidae) of Assam, northeast India. International Journal of Food Sciences and Nutrition 2(4), 38-42.

Nel JL, Le Maitre DC, Roux DJ, Colvin C, Smith JS, Smith-Adao LB, Sitas N. 2017. Strategic water source areas for urban water security: Making the connection between protecting ecosystems and benefiting from their services. Ecosystem services 28, 251-259.

Pemberton RW. 1995. Catching and eating dragonflies in Bali and elsewhere in Asia. American Entomologist 41(2), 97-99.

Qiao R, Sheng C, Lu Y, Zhang Y, Ren H, Lemos B. 2019. Microplastics induce intestinal inflammation, oxidative stress, and disorders of metabolome and microbiome in zebrafish. Science of the Total Environment 662, 246-253.

Redondo-Hasselerharm PE, Falahudin D, Peeters ET, Koelmans AA. 2018. Microplastic effect thresholds for freshwater benthic macroinvertebrates. Environmental science \& technology 52(4), 2278-2286.

Rhodes CJ. 2019. Solving the plastic problem: From cradle to grave, to reincarnation. Science progress 102(3), 218-248.

Rummel CD, Löder MG, Fricke NF, Lang T, Griebeler EM, Janke M, Gerdts G. 2016 .Plastic ingestion by pelagic and demersal fish from the North Sea and Baltic Sea. Marine pollution bulletin, 102(1), 134-141.

Thompson RC, Olsen Y, Mitchell RP, Davis A, Rowland SJ, John AW, Russell AE. 2004. Lost at sea: where is all the plastic?. Science 304 (5672), 838.

Victor TJ, Ruben R. 1999. Population dynamics of mosquito immature and the succession in abundance of aquatic insects in rice fields in Madurai, South India. Indian Journal of Malariology 36, 19-32. 
337 Wakhid W, Rauf A, Krisanti M, Sumertajaya IM, Maryana N. 2020. Species richness and 338 diversity of aquatic insects inhabiting rice fields in Bogor, West Java, Indonesia. Biodiversitas 339 Journal of Biological Diversity 21(1), 34-42.

340 Warren A. 1915. A study of the food habits of the Hawaiian dragonflies or Pinau with reference 341 to their economic relation to other insects. College of Hawaii Publications, Bulletin 3. 45 pp.

342 Williams DD, Williams SS. 2017. Aquatic insects and their potential to contribute to the diet of 343 the globally expanding human population. Insects 8(3), 72.

344 Windsor FM, Tilley RM, Tyler CR, Ormerod SJ. 2019. Microplastic ingestion by riverine 345 macroinvertebrates. Science of the total environment 646, 68-74.

346 Woodall LC, Sanchez-Vidal A; Canals M, Paterson GLJ, Coppock R, Sleight V, Calafat A, 347 Rogers AD, Narayanaswamy BE, Thompson RC. 2014. The deep sea is a major sink for 348 microplastic debris. Royal Society open science 1(4), 140317.

349 Wright SL, Thompson RC, Galloway TS. 2013 .The physical impacts of microplastics on marine organisms: a review. Environmental pollution 178, 483-492.

Xiaoming C, Ying F, Hong Z, Zhiyong C. 2010. Review of the nutritive value of edible insects. Edible insects and other invertebrates in Australia: future prospects. Proceedings of a Workshop on Asia-Pacific Resources and their Potential for Development, 19-21 February 2008, Bangkok 354 (2010), pp. 85-92. review on methods, occurrence, and sources. Science of the Total Environment 754, 141948.

357 Ying F, Xiaoming C, Shaoyun W, Shoude Y, Yong C. 2001. Three edible Odonata species and 358 their nutritive value. Forest Research 14(4), 421-424. Sdn. Bhd. Selangor, Malaysia. 
Figure 1

Site of sampling collection (N $14^{\circ} 00^{\prime} 32.2474^{\prime \prime}$ E $99^{\circ} 58^{\prime} 54.1744$ ).

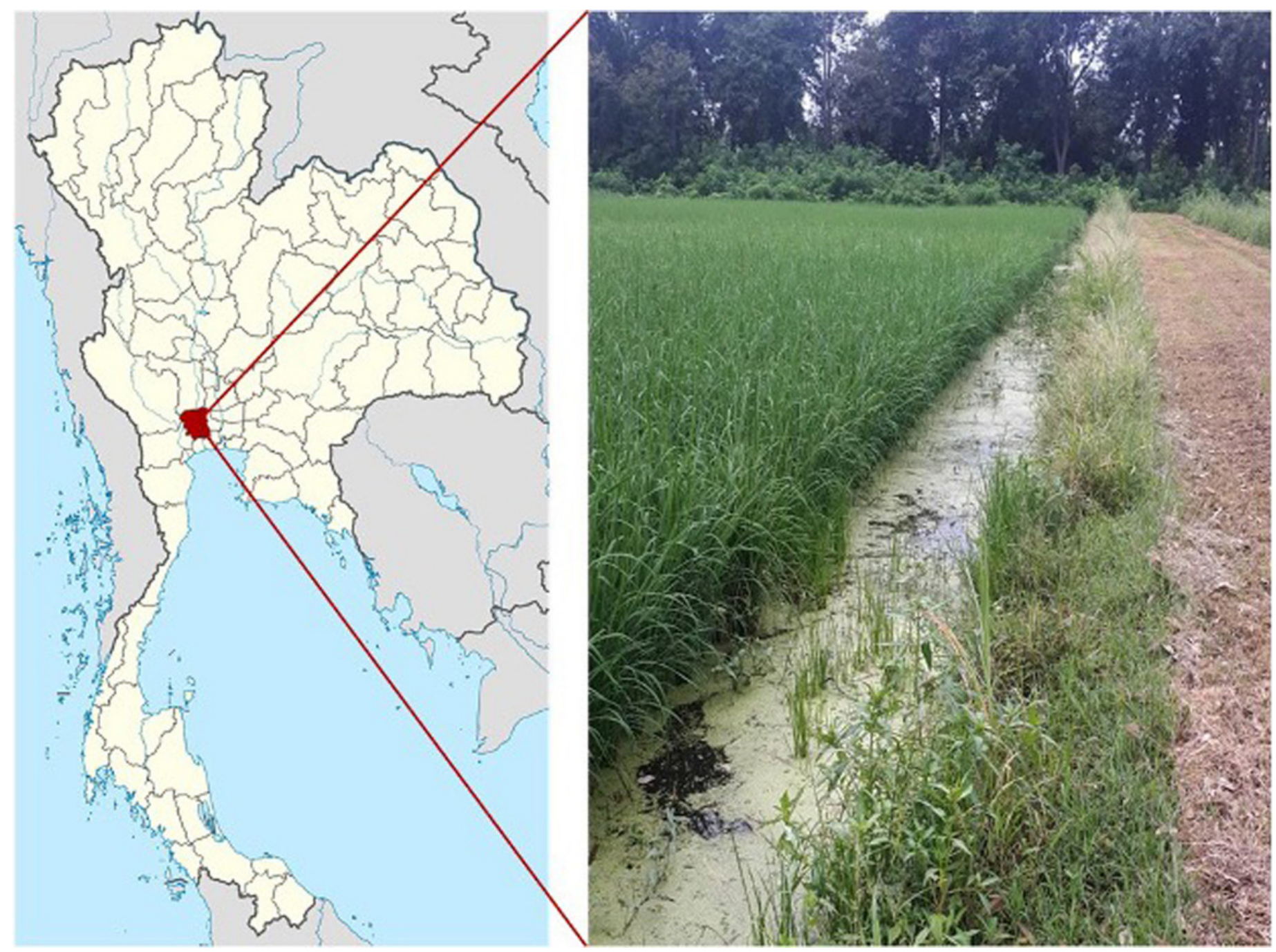


Figure 2

a. - b. Morphology of Pantala sp. (Libellulidae) nymph; c. - d. deep fried chicken egg with nymph, a popular northern Thai meal.
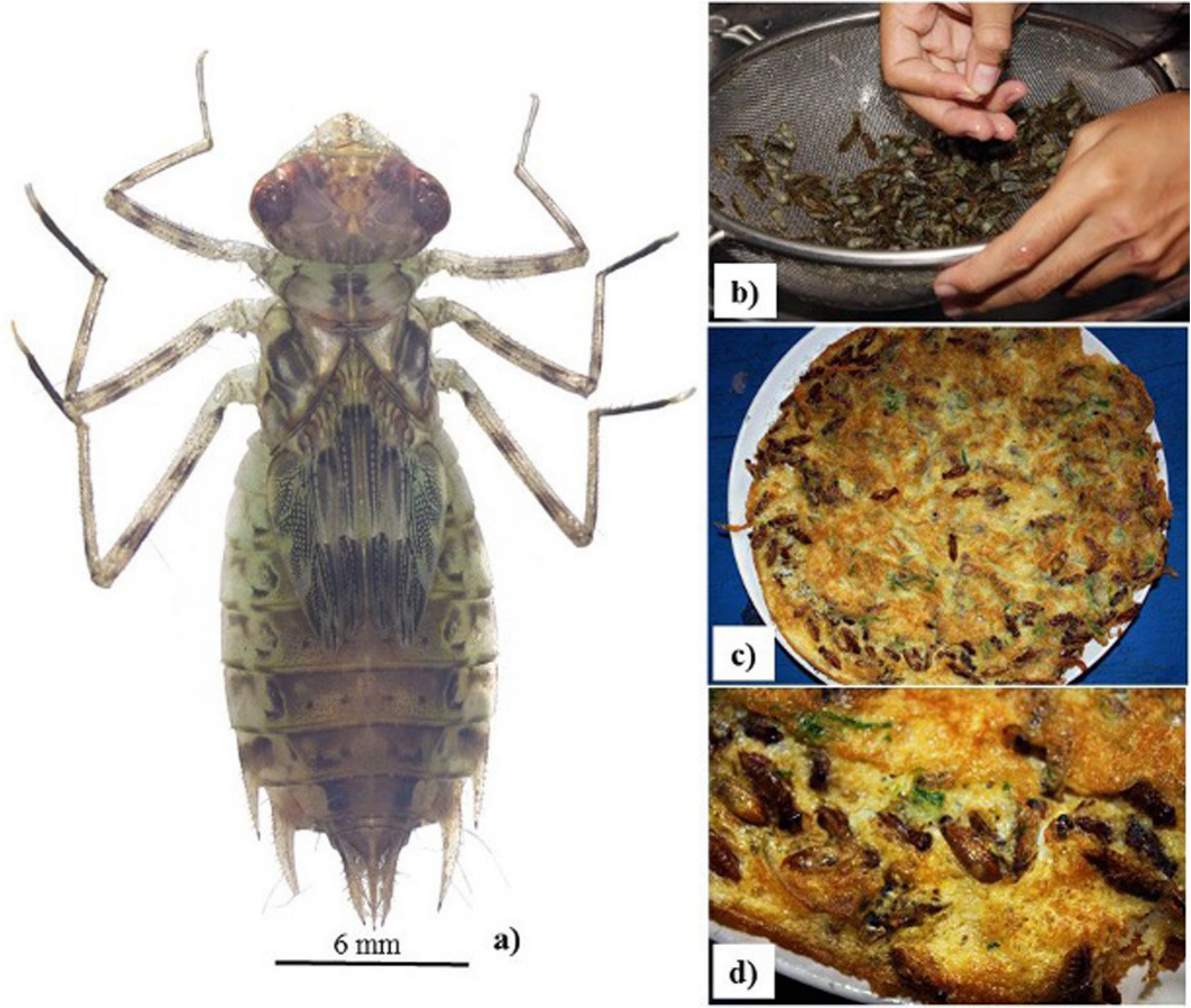
Figure 3

Comparison of the abundance (A-C), type (D-F), and color (G-I) of MPs in Pantala sp. Abbreviation: C, control.

Whole body
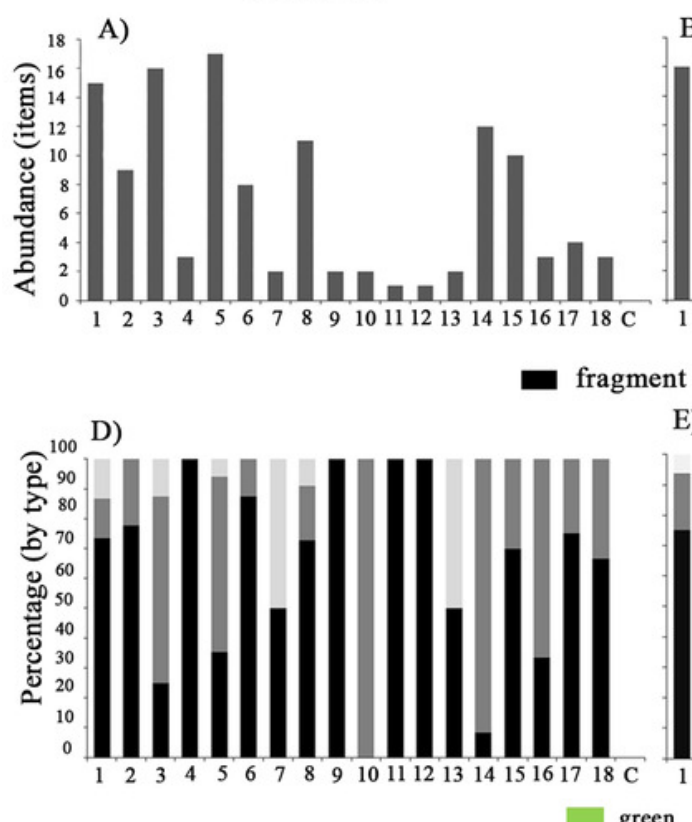

GT

B)

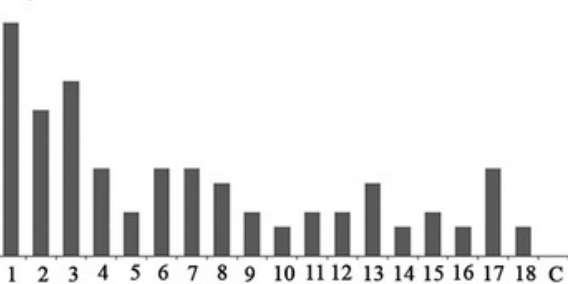

C)

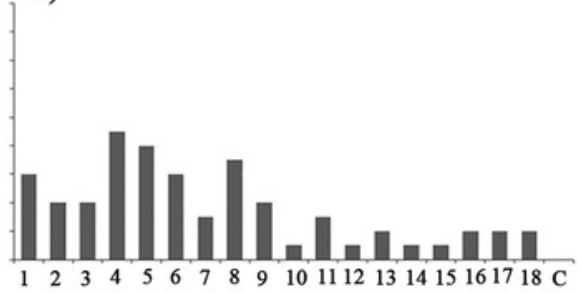

E)

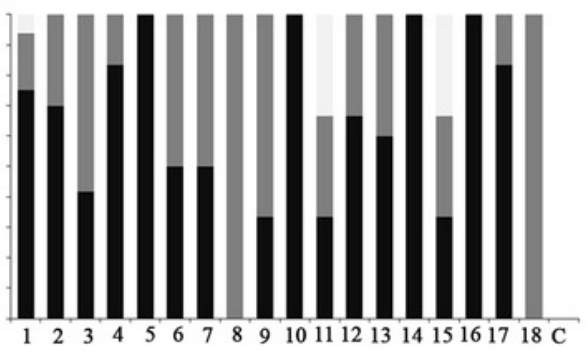

F)

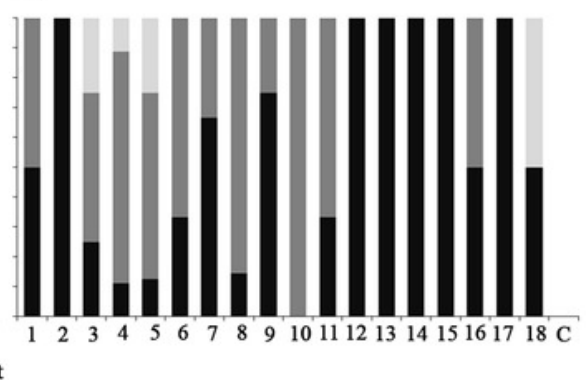

G)

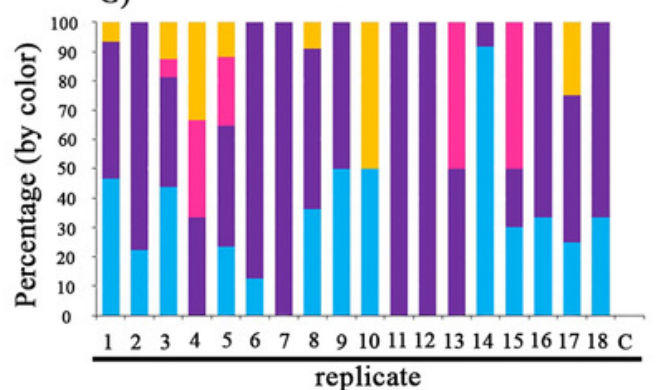

$\mathrm{H})$

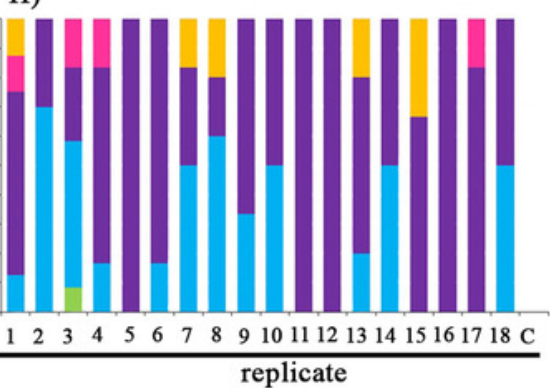

I)

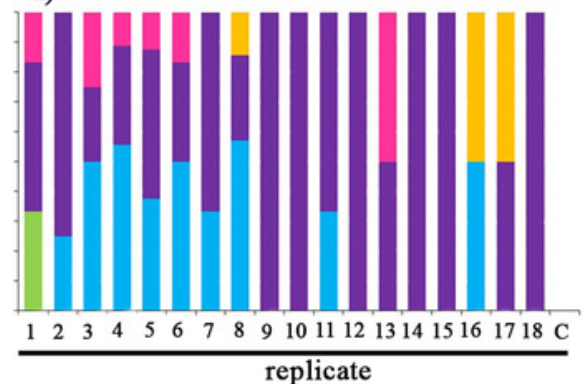


Figure 4

FTIR spectra of representative MP polymers.

The black spectrum is that of the FT-IR measurement, while the red spectrum is the reference spectrum from the Bruker spectrum library. The black arrows in the photographs indicate the particles that were identified. 

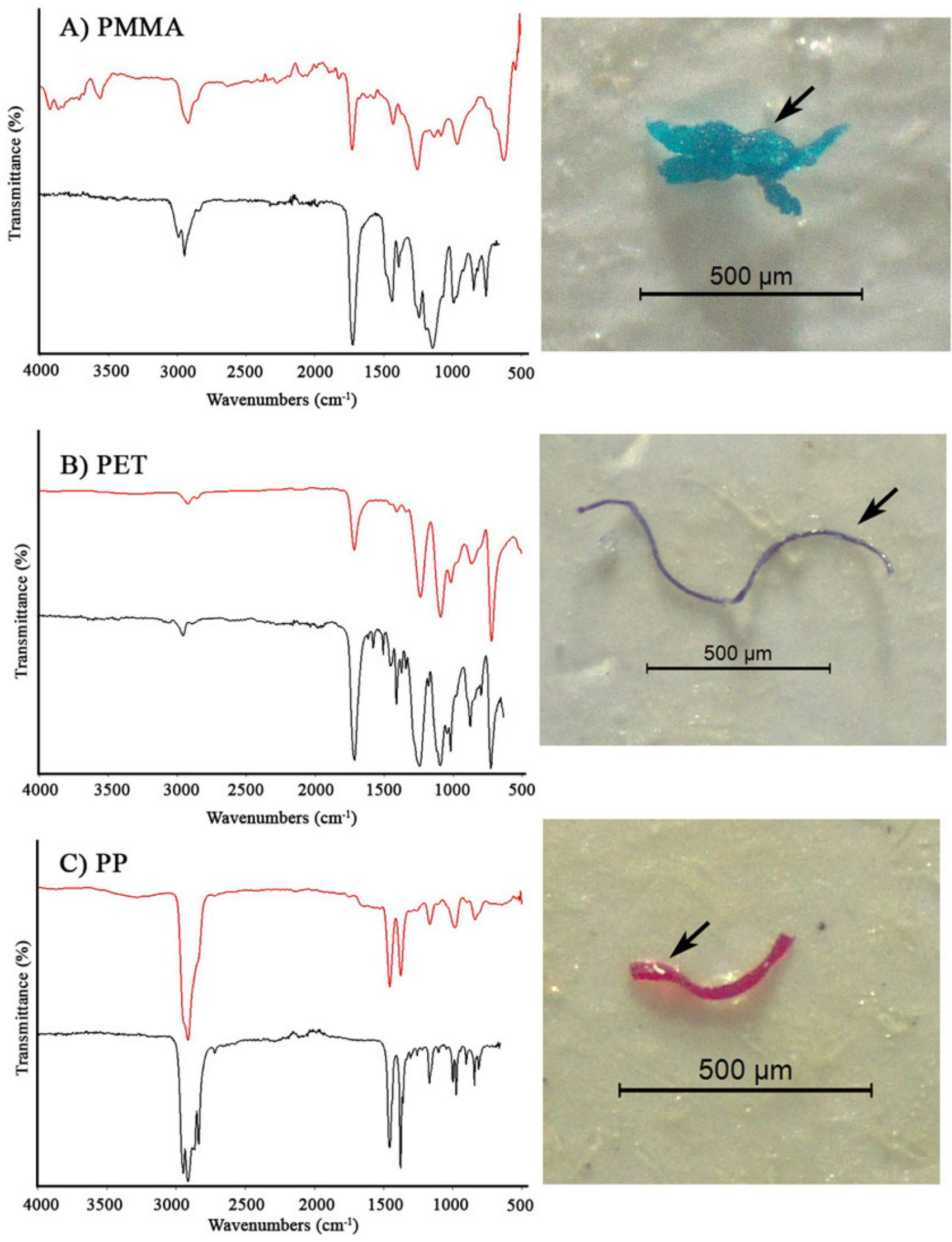


\section{Table $\mathbf{1}$ (on next page)}

MPs inspected in the three sample types.

* No significant difference at $p=0.250$ (Kruskal-Wallis H test) 


\begin{tabular}{|c|c|c|c|}
\hline sample type & wet weight $(\mathrm{g})$ & $\begin{array}{c}\text { total number } \\
\text { of particles }\end{array}$ & $\begin{array}{c}\text { mean abundance/ } \\
\text { individual* }\end{array}$ \\
\hline $\begin{array}{c}\text { whole body }(\mathrm{n}=90) \\
\begin{array}{c}\text { gastrointestinal tract (GT) only } \\
(\mathrm{n}=90)\end{array}\end{array}$ & $0.3098 \pm 0.0795$ & 121 & $1.34 \pm 1.11$ \\
\hline body without GT $(\mathrm{n}=90)$ & $0.2445 \pm 0.0707$ & 66 & $1.06 \pm 0.77$ \\
\hline
\end{tabular}

1 


\section{Table 2 (on next page)}

Types of MPs identified with FTIR

${ }^{a}$ The percentage of MP particles in all the measured particles. ${ }^{b}$ The percentage of each type in all the MP particles. 


\begin{tabular}{|l|c|c|c|c|c|c|c|c|}
\hline & \multicolumn{2}{|c|}{ Whole body } & \multicolumn{2}{|c|}{ GT } & \multicolumn{2}{c|}{$\begin{array}{c}\text { Body without the } \\
\text { GT }\end{array}$} & \multicolumn{2}{c|}{ total } \\
\hline & no. & $\%$ & no. & $\%$ & no. & $\%$ & no. & $\%$ \\
\hline particles measured & 21 & 100 & 14 & 100 & 17 & 100 & 52 & 100 \\
\hline MP particles & 10 & $47.6^{\mathrm{a}}$ & 5 & 35.7 & 9 & 52.9 & 24 & 46.1 \\
\hline polyethylene terephthalate (PET) & 7 & $70.0^{\mathrm{b}}$ & 5 & 100.0 & 5 & 55.6 & 17 & 70.8 \\
\hline polypropylene (PP) & 2 & 20.0 & 0 & 0 & 4 & 44.4 & 6 & 25.0 \\
\hline $\begin{array}{l}\text { polymethyl methacrylate } \\
\text { (PMMA) }\end{array}$ & 1 & 10.0 & 0 & 0 & 0 & 0 & 1 & 4.2 \\
\hline non MP particles & 3 & 14.3 & 4 & 28.6 & 1 & 5.9 & 8 & 15.4 \\
\hline cellulose powder & 1 & 33.3 & 1 & 25.0 & 0 & 0 & 2 & 25.0 \\
\hline polyethylene glycol & 2 & 66.7 & 2 & 50.0 & 0 & 0 & 4 & 50.0 \\
\hline xanthan gum & 0 & 0 & 1 & 25.0 & 0 & 0 & 1 & 12.5 \\
\hline hydroxyethyl cellulose & 0 & 0 & 0 & 0 & 1 & 100.0 & 1 & 12.5 \\
\hline unidentified particles & 8 & 38.1 & 5 & 35.7 & 7 & 41.2 & 20 & 38.5 \\
\hline
\end{tabular}

1 